\title{
Interactive comment on "Assessment of urban aerosol pollution over Moscow megacity by MAIAC aerosol product” by Ekaterina Y. Zhdanova et al.
}

\section{Anonymous Referee \#1}

Received and published: 10 November 2019

The submitted manuscript entitled "Assessment of urban aerosol pollution over Moscow megacity by MAIAC aerosol product" presents an important application of MAIAC AOD retrievals over urban mega-city environment. I would like to recommend the publication however after the paper major revision. For my opinion, authors need to make additional effort to improve the manuscript before its acceptance. Below are my suggestions.

General comments:

1. I think it will be great if authors provide spatial and seasonal/temporal average pattern of AOD. Furthermore, on AOD images all important geographic locations must be shown: suburban cities, city center, etc. Readers are not familiar with Moscow geography and it is difficult to follow authors results. Also at the beginning authors 
need to explain the differences between New Moscow and Old Moscow under section of "Study Area". And where are these regions on the map? Otherwise i discovered AMTD the differences in pollution pattern between both parts only at the end of a paper. Introduction should be devoted to the previous studies done in the subject that are the most relevant to the authors study rather than to study area explanation that should be only briefly explained.

Interactive comment

2. My additional comments relate to the analyses of AOD percentiles (Figure 12- which is interesting). Without a general/AOD average maps, I find it difficult to analyze results of AOD lower/upper percentiles. I also think that these analyses are speculative and must be very carefully presented, more as authors interpretation, as a "hint to local pollution", hint to regional, etc with references as done in Discussion. May be including this figure in Discussion section would be better?. And comparison with ground confirmation of these results? With some critical statements of of these results.

3. May be some figures can be removed as it reduces the paper clarity. Some figures are not explained and not well presented (details are below).

Specific/minor comments:

Introduction:

Additional literature search is required. For example: - Line 37-39: Elevated aerosol loading is generally correlated with suspended particulate matter associated with the poor air quality (van Donkelaar et al., 2015, Beloconi et al., 2018).Authors need to add additional citations that originally investigate the subject. For example, the correlation between particulate matter concentrations and AOD is not a new subject and was widely discussed. As pointed out in Hoff and Christopher 2009 (review article), different geographic locations exhibit different correlations.

Wang and Christopher 2003: Intercomparison between satellite-derived aerosol optical thickness and PM2.5 mass: Implications for air quality studies

Printer-friendly version

Discussion paper 
Hoff and Christopher 2009: Remote Sensing of Particulate Pollution from Space: Have We Reached the Promised Land? JAWMA 59(6), 645-675.

Look at Figure 3 in Chudnovsky et al. 2012 "Prediction of daily fine particulate matter concentrations using aerosol optical depth retrievals from the Geostationary Operational Environmental Satellite (GOES)" JAWMA V(62)

Interactive comment

- The use of AOD in atmospheric application is excellently presented by Kaufman et al. 2002: "A satellite view of aerosols in the climate system" published in Nature.

- Line 44: Authors stated "recent studies" Although I do not find citations to 2011 or 2013 as recent studies. I searched what was done with MAIAC recently- and perhaps can be relevant- up to authors decision of course: Barnaba et al. 2018: Satellite-based view of the aerosol spatial and temporal variability in the Córdoba region (Argentina) using over ten years of high-resolution data, ISPRS Journal of Photogrammetry and Remote Sensing. And more publications can be found.

-Line 74: "against the high-quality AERONET measurement". I would avoid such a strong statement as "high-quality" Sometimes even AERONET provide biased measurements. I would suggest "against ground-based AOD measurements".

Methods: - Methodology section and data sets-all is mixed up. One needs to dig the information. Please reorganize to sub-paragraphs MAIAC AOD, AERONET data, gaseous pollution data, study area, etc. The same is for results section.

Results: 1. Figure 2: authors need to provide equation for both plots, slope, intercept, $r$, and explain high residuals on both plots, what are possible causes.

2. I do not understand Figure 5- it says correlation, but I do not see correlation coefficient, I do not see any pattern except of lack of it. I see a scatter plot with zero correlation. What authors wanted to present? I get puzzled.

3. Figure 10: I do not understand what median AOD maps present? Why authors can't present average AOD values instead? Please justify your selection.

Printer-friendly version

Discussion paper

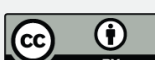


4. Figures 6 and 7 are not explained. Please provide explanations to your results.

Discussion:

AMTD

Authors need to provide discussion on points that overestimated and underestimated by MAIAC AOD retrieval at least by showing what are meteorological conditions that favor these results. I mean- analyses of residuals (from figure 2).

Interactive comment

Authors also need to state the limitations of thier results and future directions in one short paragraph.

Good Luck!

Interactive comment on Atmos. Meas. Tech. Discuss., doi:10.5194/amt-2019-325, 2019. 